\section{Biosynthesis of Shamixanthone}

\author{
Masayoshi IsHIDA, Takashi HAMASAKI* \\ and Yuichi HATSUDA*
Tottori Womens' College, Kurayoshi, Tottori *Faculty of Agriculture, Tottori University, Koyama, Tottori

Received July 11, 1977

In the previous paper, ${ }^{1)}$ we have reported the isolation of emericellin (I), shamixanthone (II) and epishamixanthone (III) from the mycelium of Aspergillus rugulosus, and the characterization of structures of I and III. The biogenesis of these metabolites are interesting in view of the fact that the $O$-isoprenyl group bonded to the xanthone nucleus of $I$ is modified to the dihydropyran ring in II and III, and the latter moiety is presumably derived from $I$ by oxidative cyclization of the $O$-isoprenyl with the hydroxymethyl group at 8-position of xanthone nucleus. The stereochemical relation between isopropenyl and hydroxyl groups on the dihydropyran ring is shown to be trans in II and cis in III.<smiles>CC(C)=CCOc1c(C)cc2oc3c(CO)ccc(O)c3c(=O)c2c1CO</smiles><smiles>C=C(C)C1COc2c(C)cc3oc4c(CC=C(C)C)ccc(O)c4c(=O)c3c2C1O</smiles><smiles>C=C(C)C1COc2c(C)cc3oc4c(CC=C(C)C)ccc(O)c4c(=O)c3c2C1O</smiles><smiles>C=C(C)C1COc2c(C)cc3oc4c(CC5OC5(C)C)ccc(O)c4c(=O)c3c2C1O</smiles>

Holker et al. have recently proposed, ${ }^{2)}$ by the experiments using of ${ }^{13} \mathrm{C}$-acetate and Aspergillus variecolor, a possible route for the biosynthesis of tajixanthone (IV), a monoepoxide derivative of II. In the present investigation we have examined the biosynthetic route of II with a strain of Aspergillus rugulosus, and now describe our experimental results on the incorporation of labeled acetate- $\left[1-{ }^{13} \mathrm{C}\right]$ into II using the ${ }^{13} \mathrm{C}$ NMR technique.

To 7-day cultures of Aspergillus rugulosus grown on malt extract medium was added sodium acetate- $\left[1-{ }^{13} \mathrm{C}\right]$ (90\%, enriched) to a concentration of $0.1 \mathrm{~g}$ per $200 \mathrm{ml}$. After an additional 14 days, the mycelium was harvested and $72 \mathrm{mg}$ per 2 liters of the isotope enriched II was isolated by the method described previously. ${ }^{\text {t) }}$

The ${ }^{13} \mathrm{C}-\mathrm{NMR}$ spectra of enriched shamixanthone $(72 \mathrm{mg})$ and its natural sample were measured in deuteriochloroform with tetramethylsilane as internal standard, with a JNM-PET-100 (25.15 MHz) spectrometer with a JEC 60 computer. Sweep widths of $6250 \mathrm{~Hz}$ with 8192 plot data points and repetition rate $2.0 \mathrm{sec}$. (1800 scans) were used.

The results are shown in Fig. 1. The assignments of ${ }^{18} \mathrm{C}$ resonances in the spectrum of 11 were made by comparing them with those reported in literature. ${ }^{2)}$ The computer-listed relative intensities of individual signals in the ${ }^{13} \mathrm{C}$-NMR spectra of natural and ${ }^{13} \mathrm{C}$ enriched shamixanthons are shown in Table 1 .

Table I. Computer-Listed Relative INTENSITIES OF INDIVIDUAL SIGNALS IN THE ${ }^{13} \mathrm{C}$-NMR SPECTRA OF SHAMTXANTHONE

\begin{tabular}{|c|c|c|c|c|}
\hline \multirow{2}{*}{ Carbon } & \multirow{2}{*}{$\begin{array}{l}\text { Signal } \\
(\mathrm{ppm})\end{array}$} & \multicolumn{2}{|c|}{$\begin{array}{l}\text { Observed intensities } \\
\left(\times 10^{3}\right)\end{array}$} & \multirow{2}{*}{$\begin{array}{c}\text { Relative } \\
\text { intensities }\end{array}$} \\
\hline & & Natural & $\begin{array}{l}\text { Acetate- }[1- \\
\left.{ }_{13} \mathrm{C}\right] \text { derived }\end{array}$ & \\
\hline 1 & 152.6 & 0.80 & 1.93 & $2.41^{0)}$ \\
\hline 2 & 109.7 & 3.06 & 3.67 & 1.20 \\
\hline 3 & 136.4 & 3.76 & 6.15 & $1.64^{a \lambda}$ \\
\hline 4 & 118.8 & 2.30 & 2.12 & 0.92 \\
\hline 5 & 119.2 & 3.62 & 3.57 & 0.98 \\
\hline 6 & 138.1 & 1.63 & 3.36 & $2.06^{a 3}$ \\
\hline 7 & 149.4 & 1.47 & 1.93 & 1.31 \\
\hline 8 & 120.9 & 1.79 & 3.25 & $1.82^{a)}$ \\
\hline 9 & 109.1 & 1.14 & 1.32 & 1.16 \\
\hline 10 & 159.7 & 1.83 & 4.55 & $2.49^{a)}$ \\
\hline 11 & 152.1 & 1.22 & 2.66 & $2.18^{a}$ \\
\hline 12 & 116.8 & 0.81 & 1.17 & 1.44 \\
\hline 13 & 184.3 & 1.35 & 2.80 & $2.07^{a)}$ \\
\hline 19 & 17.4 & 2.45 & 2.82 & 1.15 \\
\hline 25 & 63.2 & 3.55 & 4.01 & 1.13 \\
\hline 14 & 27.5 & 3.28 & 4.11 & $1.25^{a)}$ \\
\hline 15 & 121.7 & 3.34 & 3.86 & 1.16 \\
\hline 16 & 133.2 & 1.20 & 3.01 & $2.50^{a>}$ \\
\hline 17 & 17.9 & 1.76 & 2.04 & 1.16 \\
\hline 18 & 25.8 & 2.29 & 2.39 & 1.04 \\
\hline 20 & 64.6 & 3.00 & 4.20 & $1.40^{a)}$ \\
\hline 21 & 45.0 & 3.57 & 4.26 & 1.19 \\
\hline 22 & 142.6 & 2.33 & 4.50 & $1.94^{a>}$ \\
\hline 23 & 112.2 & 3.12 & 3.21 & 1.03 \\
\hline 24 & 22.5 & 2.35 & 2.27 & 0.97 \\
\hline
\end{tabular}

a) Labeled by acetate- $\left[1-{ }^{13} \mathrm{C}\right]$.

The significant enhancements in signal intensities of $\mathrm{C}-1, \mathrm{C}-3, \mathrm{C}-6, \mathrm{C}-8, \mathrm{C}-10, \mathrm{C}-11, \mathrm{C}-13, \mathrm{C}-16$ and $\mathrm{C}-$ 22 over the corresponding natural abundances clearly indicated that these carbons should be originated from the carboxyl carbon of acetate- $\left[1-{ }^{13} \mathrm{C}\right]$. On the other hand, the relatively weak intensities of signal heights 


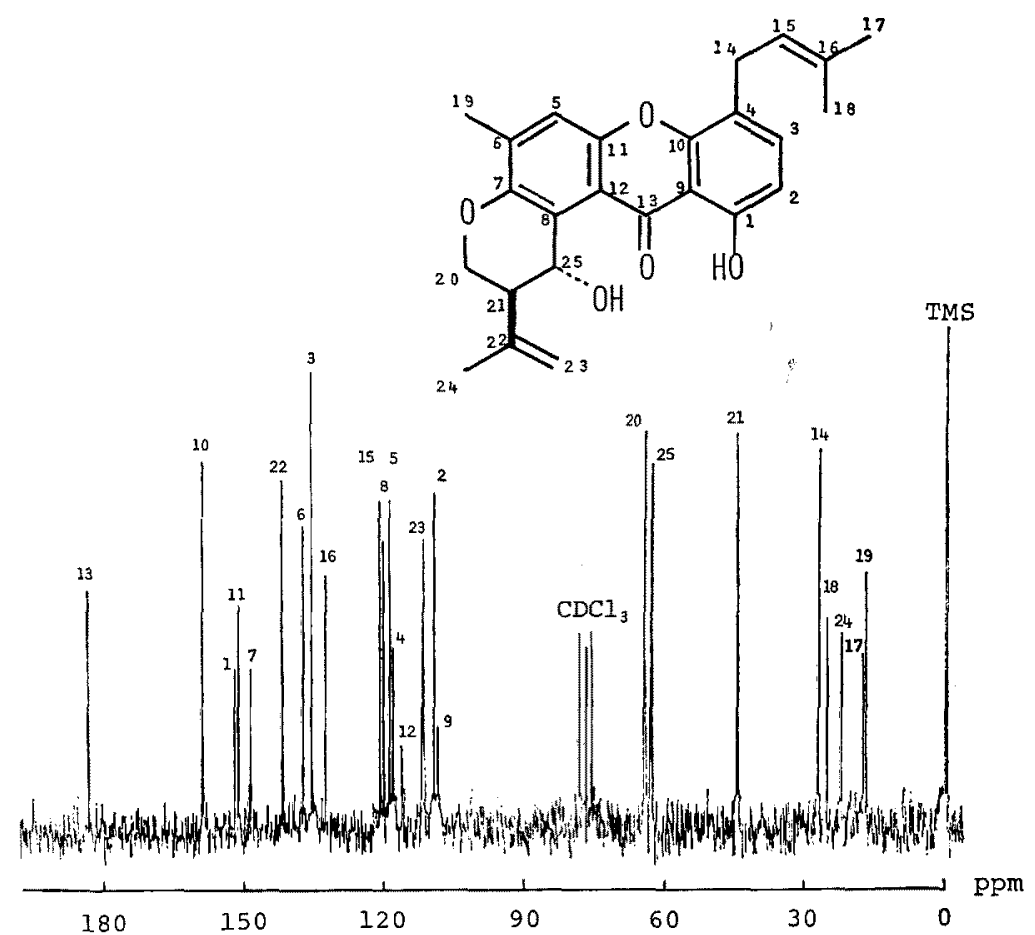

FIG. 1. ${ }^{13} \mathrm{C}-\mathrm{NMR}$ Spectrum of Shamixanthone from Acetate-[1-138 $\left.\mathrm{C}\right]$ in $\mathrm{CDCl}_{3}$.

for $\mathrm{C}-14$ and $\mathrm{C}-20$ made it difficult to discuss the isotopic enrichments on the whole. However, we estimated these two carbons to be the labeled ones, because they had relatively high levels of intensity among the side chain carbons. The isotopic enhancements for $\mathrm{C}-21$ and $\mathrm{C}-25$ were not observed; these carbons may have been derived from methyl groups of acetates. Based on ${ }^{13} \mathrm{C}-\mathrm{NMR}$ analysis as well as the above-<smiles>C=C(C)C1COc2c(C)cc3oc4c(CC=C(C)C)ccc(O)c4c(=O)c3c2C1O</smiles>

FIG. 2. Labeling Pattern of Shamixanthone. mentioned consideration, the incorporation of acetate$\left[1{ }^{13} \mathrm{C}\right]$ in $I I$ may be concluded as shown in Fig. 2.

This labeling pattern supports the theory that the xanthone skeleton in shamixanthone is derived from heptaketide and two isoprenyl moieties from mevalonate.

Acknowledgement. The authors wish to thank Professor Mikio Yamazaki of Chiba University for the measurements of the ${ }^{13} \mathrm{C}$-NMR spectra.

\section{REFERENCES}

1) M. Ishida, T. Hamasaki, Y. Hatsuda, K. Fukuyama, T. Tsukihara and Y. Katsube, Agric. Biol. Chem., 39, 291 (1975); 40, 1051 (1976).

2) J. S. E. Holker, R. D. Lapper and T. J. Simpson, J. Chem. Soc. Perkin Trans. I, 1974, 2135. 